\title{
Where did it come from, where do you go? Direction sources influence navigation decisions during spatial uncertainty
}

Brunyé, T.T.; Gagnon, S.A.; Gardony, A.L.; Gopal, N.H.; Taylor, H.A.; Tenbrink, T.

\section{Quarterly Journal of Experimental Psychology}

DOI:

$10.1080 / 17470218.2014 .963131$

Published: 06/10/2014

Peer reviewed version

Cyswllt i'r cyhoeddiad / Link to publication

Dyfyniad o'r fersiwn a gyhoeddwyd / Citation for published version (APA):

Brunyé, T. T., Gagnon, S. A., Gardony, A. L., Gopal, N. H., Taylor, H. A., \& Tenbrink, T. (2014). Where did it come from, where do you go? Direction sources influence navigation decisions during spatial uncertainty. Quarterly Journal of Experimental Psychology, 68(3), 585-607. https://doi.org/10.1080/17470218.2014.963131

\section{Hawliau Cyffredinol / General rights}

Copyright and moral rights for the publications made accessible in the public portal are retained by the authors and/or other copyright owners and it is a condition of accessing publications that users recognise and abide by the legal requirements associated with these rights. study or research.

- Users may download and print one copy of any publication from the public portal for the purpose of private

- You may not further distribute the material or use it for any profit-making activity or commercial gain

- You may freely distribute the URL identifying the publication in the public portal ?

Take down policy

This is an Accepted Manuscript of an article published by Taylor \& Francis in The Quarterly Journal of Experimental Psychology on 6 October 2014, available online: http://wwww.tandfonline.com/ DOI http://dx.doi.org/10.1080/17470218.2014.963131

Take down policy

If you believe that this document breaches copyright please contact us providing details, and we will remove access to the work immediately and investigate your claim. 
Running head: NAVIGATION UNCERTAINTY

Where did it come from, where do you go? Direction sources influence

navigation decisions during spatial uncertainty

\author{
Tad T. Brunyé ${ }^{1,3}$ \\ Stephanie A. Gagnon ${ }^{1,2,3}$ \\ Aaron L. Gardony ${ }^{1,3}$ \\ Nikhil Gopal ${ }^{1}$ \\ Amanda Holmes ${ }^{1}$ \\ Holly A. Taylor ${ }^{1}$ \\ Thora Tenbrink ${ }^{4}$ \\ ${ }^{1}$ Tufts University, Department of Psychology, Medford, MA \\ ${ }^{2}$ Stanford University, Department of Psychology, Stanford, CA \\ ${ }^{3}$ U.S. Army Natick Soldier Research, Development, and Engineering Center, \\ Cognitive Science Team, Natick, MA \\ ${ }^{4}$ Bangor University, School of Linguistics, Bangor, LL57 2DG, UK
}

\title{
Contact Author
}

Tad T. Brunyé, Ph.D.

Tufts University

Department of Psychology

490 Boston Ave.

Medford, MA 02155

Tel: 617-627-4075

tbruny01@tufts.edu 


\begin{abstract}
Previous research on route directions largely considers the case when a knowledgeable routegiver conveys accurate information. In the real world, however, route information is sometimes inaccurate and directions can lead navigators astray. We explored how participants respond to route directions containing ambiguities between landmarks and turn directions, forcing reliance on one or the other. In three Experiments, participants read route directions (e.g., To get to the Metro Station, take a right at the Pharmacy.) and then selected from destinations on a map. Critically, in half of the trials the landmark (Pharmacy) and turn (right) directions were conflicting, such that the participant had to make a decision under conditions of uncertainty; under these conditions, we measured whether participants preferentially relied upon landmarkversus direction-based strategies. Across the three Experiments, participants were either provided no information regarding the source of directions (Experiment 1), told that the source of directions was a GPS device (Experiment 2), or a Human (Experiment 3). Without information regarding the source of directions, participants generally relied on landmarks or turn information under conditions of ambiguity; in contrast, with a GPS source participants relied primarily on turn information, and with a Human source on landmark information. Results were robust across gender and individual differences in spatial preference. We discuss these results within the context of spatial decision making theory, and consider implications for the design and development of landmark-inclusive navigation systems.
\end{abstract}

Keywords: navigation, spatial cognition, decision-making, GPS, uncertainty 
Where did it come from, where do you go? Direction sources influence navigation decisions during spatial uncertainty

Navigating unfamiliar environments based on digital or human route guidance has become a ubiquitous activity for both pedestrians and drivers. Consider attending an academic conference in an unfamiliar city and asking a passerby for directions - for instance, how to walk to the nearest metro station. The passerby is likely to provide route instructions that include explicit reference to landmarks (e.g., a salient business), turns, and distances (Denis, Pazzaglia, Cornoldi, \& Bertolo, 1997). For instance, continue forward and turn right at the pharmacy. In many cases, the instructions will prove successful in guiding you to the metro station; in other cases, however, the passerby will unwittingly provide you with incorrect, incomplete or conflicting information (Lovelace, Hegarty, \& Montello, 1999; Vanetti \& Allen, 1988). For instance, after traveling for three blocks you see a pharmacy, but only a left turn; there is a right turn in the distance, but no adjacent pharmacy. Which information would you rely upon, the landmark or the turn direction? How might this change as a function of the information source? These questions form the basis of the present research. To motivate our studies and inform our hypotheses, we consider two largely disparate extant literatures: (1) studies considering the types of information navigators expect and need in order to effectively find goal destinations, and (2) studies considering the strategies people use when making decisions under uncertainty.

\section{Developing and Using Route Descriptions}

Goal-directed navigation is one of the most fundamental and important human behaviors (Montello, 2005), affording successful locomotion through both simple and complex environments. In general, humans navigate through familiar environments by relying upon a dynamic interaction between the directly perceived world and memory for the learned space. Underlying this interaction are at least five navigation strategies that have been clearly defined, including locomotor guidance, landmark navigation, path integration, route-based navigation, and map-based navigation (Foo, Warren, Duchon, \& Tarr, 2005; Trullier, Wiener, Berthoz, \& Mayer, 1997). In general, these strategies range from basic stimulus-response mechanisms such as routinely navigating a well-learned route-based sequence, to higher-level strategies such as understanding the spatial structure of an environment and deriving novel routes (e.g., short-cuts). 
Presently we focus on the application of route-based sequences, though we acknowledge that humans likely rely upon multiple strategies during real-world navigation, particularly in welllearned environments. For instance, when navigators hold extensive knowledge regarding both well-learned routes and the overall environment structure, they may more flexibly shift between landmark-based, route-based, and overall layout-based strategies for resolving difficulties during navigation (e.g., encountering detours; Janzen, Schade, Katz, \& Herrmann, 2001). In the present research we consider cases when navigators encounter and attempt to identify appropriate routes in novel environments.

Route-based navigation involves remembering and applying knowledge about the sequences of routes, orientations, and landmarks and views along the way (O'Keefe \& Nadel, 1978). In contrast to mental representations more analogous to a cartographer's map, route knowledge consists of relatively inflexible sequences towards a goal, and these sequences must be followed in an exacting manner. Such path sequences might integrate turn and landmark information, such as Turn left at the pharmacy, and then right at the bakery to get to the bowling alley; however this route information would not include other spatial knowledge, for instance, the fact that one might also be able to reach the bowling alley by continuing straight past the pharmacy, and taking a left at another landmark to move in the destination's general direction. For this reason, unsuccessfully following a route sequence in an unfamiliar environment inevitably leads to the accumulation of errors and possibly failure to find a goal destination (Daniel, Tom, Manghi, \& Denis, 2003; Denis et al., 1997; Tom \& Denis, 2003).

The majority of research examining route directions can be divided into two general categories; that identifying the frequently used content of route descriptions (Allen, 2000; Denis, 1997; Denis et al., 1997, studies 1-3; Golding, Graesser, \& Hauselt, 1996; Lloyd, 1997; Lovelace et al., 1999; Streeter, Vitello, \& Wonsiewicz, 1985; Tversky \& Lee, 1999; Vanetti \& Allen 1988), and that examining navigation successes and failures when following particular types of route directions (Daniel et al., 2003, Daniel, Przytula, \& Denis, 2009; Daniel \& Denis, 1998; Denis et al., 1997, study 4). The results and implications of these studies are quite similar. In general, Denis and colleagues have demonstrated several skeletal characteristics of route descriptions deemed critical for navigation success. These include the minimal and essential landmark information (e.g., indicating landmark identities adjacent to turns) and a set of 
instructions (e.g., travel distances and turn directions); in general, the effectiveness of route descriptions is contingent upon whether they accurately link the descriptive (landmarks) to the prescriptive (action repertoire; Daniel et al., 2009). Landmarks have been repeatedly demonstrated as essential elements of route directions, with particular importance for identifying origins, decision points, and destinations (Klippel \& Winter, 2005; Michon \& Denis, 2001; Tversky \& Lee, 1999). Distant landmarks, for instance a mountain range or tall building, can also provide global awareness and aid in orientation relative to an environment's overall structure (Steck \& Mallot, 2000). For these reasons, recent research and development efforts in spatial information technologies are exploring the potential utility of incorporating salient landmarks into digital navigation supports (Burnett, 2000; Duckham, Winter, \& Robinson, 2010; Millonig \& Schechtner, 2007; Schroder, Mackaness, \& Gittings, 2011).

Designing and developing next-generation navigation technologies is contingent upon fully characterizing how users behave in unfamiliar environments, including their relative dependence on environmental features and prescribed directions (Taylor, Brunyé, \& Taylor, 2009). The current emphasis on incorporating landmarks into handheld and in-vehicle navigation technologies (Rehrl, Häusler, \& Leitinger, 2010; Schmid, Kuntzsch, Winter, Kazerani, \& Preisig, 2010) must be complemented by research attempting to understand the conditions under which this capability will aid versus hinder efficient navigation. Incorporating landmarks into navigation devices represents a promising avenue for promoting navigation accuracy (Pauzié, Daimon, Bruyas, \& Trauchessec, 1997) but also a major investment in maintaining updated landmark location databases. For instance, consider the case of relocated landmarks, such as a major coffee house moving east two blocks. Given individuals' apparently strong reliance on landmarks for guiding navigation (Klippel \& Winter, 2005; Michon \& Denis, 2001; Tversky \& Lee, 1999), landmark-inclusive navigation devices might prove to reduce performance when referenced landmarks deviate from an expected location.

Though several studies have clearly demonstrated that navigation performance suffers in the absence of expected landmarks (Müller \& Wehner, 1988; Wehner, 1992), no studies have examined relative reliance on landmarks versus turn directions in guiding navigation, and how this reliance might change as a function of the information source. Unambiguous route directions certainly demonstrate the utility of landmarks in marking the onset of a prescriptive instruction 
(e.g., turn right at the pharmacy); we will call a preferential reliance on landmarks during navigation an indication of a landmark-based strategy. However, it is also clear that turn directions can signal the coarse global direction of a goal destination (Dalton, 2003; Hochmair \& Frank, 2002). This direction-based strategy relies on a visual and imagery-based process that derives the angular difference between the distant goal and the perceived paths and intersections (Hölscher, Tenbrink, \& Wiener, 2011; Chown, Kaplan, \& Kortenkamp, 1995).

\section{Spatial Decision Making under Uncertainty}

There are several possible events that can trigger uncertainty on behalf of a navigator. For instance, landmarks can move, direction-givers can provide incorrect turn directions or landmark identities, or navigators can fail to recall correct procedures. Direction-givers may not explicitly signal (Hirtle, Richter, \& Srinivas, 2010) where in a route such difficulties may arise (e.g., "This is the tricky part..."), and cases of uncertainty may trigger strategy shifts on behalf of a navigator. For instance, unreliable landmarks can force reliance on a direction-based strategy (Foo et al., 2005); in this case, if a route description calls for a right turn at the pharmacy, the navigator might infer that the metro station is generally ahead and to the right. When people are directly asked what type of information they would want someone to provide to direct their navigation, they rate turn directions as the most important, followed by landmarks (Burns, 1997). Thus, this specific evidence suggests that turn direction might be highly relied upon under unambiguous conditions, or conditions of landmark ambiguity. However, research into strategy adoption under conditions of uncertainty is rather limited. In general, this research demonstrates that navigators make decisions by comparing their memory for the environment with their unfolding perceptual and motor experiences in the world (Gärling, 1995; Russell \& Ward, 1982). Gärling and Golledge (2000) propose a hierarchy of spatial decisions defining interactions between perception, memory, and internal thought processes that allow for the development, evaluation and choice of alternatives. Specifically, the model proposes that individuals begin navigation with an explicit goal (e.g., find the nearest metro station), retrieve alternative routes from memory, evaluate alternatives based on attributes (e.g., efficiency, familiarity, directness), and then select and implement a choice. This model of spatial decision making depends on either direct perception of a goal (e.g., seeing the metro station in the distance), or stored environmental knowledge (e.g., a cognitive map of the environment). Related models have a similar emphasis 
(i.e., Gärling, Book, \& Lindberg, 1984; Lawton, 1996; Passini, 1980; Russell \& Snodgrass, 1987). More recently, Hölscher, Tenbrink, \& Wiener (2011) showed how navigators adapt their previous route plans incrementally based on updated perceptual information during navigation.

Thus, while several advances have been made in understanding how individuals develop and apply spatial knowledge during navigation, very limited work has investigated the case of individuals navigating within novel environments. In other words, when an individual cannot rely upon stored memory representations to inform route selection, how do they behave when they encounter uncertainty? Answering this type of question reflects a structural approach to decision making (i.e., Payne, 1976) that considers how route choices are related to at least the: attributes of route options, situational factors, and characteristics of the individual navigator. Factors internal to individuals may include both individual spatial preferences, such as preferring to think about routes versus overall structure of an environment (Münzer \& Hölscher, 2011; Pazzaglia, Cornoldi, \& De Beni, 2000), or individual biases or rules-of-thumb that people apply to inform decisions when uncertain (Timmermans, 1983; Kahneman \& Tversky, 1982). Some decision making models propose that individuals have learned adaptations to particular situations that guide decisions and often circumvent difficult trade-offs that characterize fully considering all options and reaching a rational decision (Gigerenzer \& Goldstein, 1996). Within the spatial domain, extant research has suggested that heuristics account for a wide range of navigation behavior when people select and follow routes through unfamiliar environments. For instance, navigators tend to select routes that: $(a)$ have fewer turns and landmarks moving toward a destination (Sadalla \& Staplin, 1980; Senevirante \& Morrall, 1986), (b) deviate minimally from the overall direction of a destination (Dalton, 2003; Hochmair \& Frank, 2000), (c) are relatively long and straight as they leave an origin (Bailenson, Shum, \& Uttal, 1998, 2000), $d$ ) use environmental clues (e.g., architectural details) to make inferences about indoor locations (Frankenstein, Büchner, Tenbrink, \& Hölscher, 2010) and (e) move generally southward rather than northward (Brunyé, Andonova, Meneghetti, Noordzij, Pazzaglia, Wienemann, Mahoney, \& Taylor, 2012; Brunyé, Mahoney, Gardony, \& Taylor, 2010). This research suggests that individuals might adopt reliance on one or more specific strategies when faced with spatial uncertainty; applying heuristics when faced with problems might reflect efforts toward cognitive economy and simplification (Gray, Sims, Fu, \& Schoelles, 2006). 


\section{Individual and Situational Predictors of Spatial Decision Making}

It could be the case that individual navigators develop preferential reliance on either landmarks or turn directions, and apply this preference across a range of situations. For instance, individual differences in navigators' preferences for landmark- versus route- or survey-based strategies (i.e., Münzer \& Hölscher, 2011; Pazzaglia et al., 2000) might predict use of either a landmark- or direction-based heuristic. Individuals with strong preferences for landmarks tend to focus on landmarks along a route that specify where and in what direction to turn (Pazzaglia \& De Beni, 2001; Shelton \& McNamara, 2004), whereas others prefer to use a relatively global direction-based cue to guide them toward a destination (Lawton, 1996). Extant decision making research, however, has clearly demonstrated decision variability as a function of not only individual differences but also situational factors that guide decisions (Lipshitz \& Strauss, 1997; Maule \& Svenson, 1993; Payne, 1976). Under these theories, any preferential reliance on behalf of navigators might further be contingent upon the characteristics of the direction-giver or tradeoffs between energy expenditure and identifying a 'good enough' solution (Kwan, Golledge, \& Speigle, 1996; March, 1994).

In general, users of in-vehicle and handheld navigation aids show high reliance and trust that the system will provide accurate route information (St. George \& Nendick, 1997). As with any automated system, however, high levels of reliance do not necessarily translate to monitoring or understanding system performance (Endsley \& Kiris, 1995; Lee \& See, 2004). At a minimum, overreliance on failing automated route directions can lead to re-routing and low efficiency; at an extreme, this type of overreliance can lead to individuals unwittingly following route guidance to the edge of a cliff (Mychalcewycz, 2009). This overreliance, however, might be minimized when a human provides the route instructions, because humans have different levels of environmental knowledge. Indeed we intuitively (and empirically; Lovelace et al., 1999) realize that someone who does not know an environment well will be more prone to errors when generating route directions. Since level of spatial knowledge is often reflected in the language people use to describe routes (Tenbrink, Bergmann, \& Konieczny, 2011), the strategies of the wayfinder can be adapted accordingly, though maybe with little awareness. 


\section{The Present Experiments}

It is unclear what information and strategies humans might preferentially rely upon when they encounter ambiguous directions, and further, how these preferences might be affected by individual differences and situational factors. For instance, consider two real-world cases of ambiguity related to our introductory example continue forward then turn right at the pharmacy:

1) The traveler finds the pharmacy, but adjacent to a left turn

2) The traveler finds a right turn, but without an adjacent pharmacy.

Without being able to garner further information, what might the traveler do in each of these cases? A landmark-based strategy predicts the following: in the first scenario, the navigator will decide to turn left, and in the second scenario, the navigator might continue past the right turn in an attempt to find a pharmacy. In contrast, a direction-based strategy predicts that the navigator will continue past the pharmacy in the first scenario (in an attempt to find a right turn), and in the second scenario take the right turn in the absence of the pharmacy. To our knowledge, no experiments have explicitly pitted landmarks and turn directions against one another in this manner. Tendencies to use landmark- or direction-based strategies might also vary as a function of individual preferences toward particular environmental information or trust in an automated or human direction giver. Specifically, we expect individual preferences and information source to predict strategy reliance during navigation. GPS devices and humans might be perceived as differentially fallible, with GPS devices perceived as fallible with regard to landmark identities, and humans fallible with regard to turn directions. Specific motivations and hypotheses related to manipulating the source of information (GPS versus human) are discussed in more detail in the respective experiments.

To test these issues we conducted three experiments. In each, participants were given route directions (e.g., To get to the metro station, take a right at the Pharmacy.) guiding them to a goal location in an unfamiliar environment characterized by paths, landmarks and intersections. The environments had a long, straight path emanating from an origin, and two short intersecting roads, one affording a left turn and one a right turn. At the end of each intersecting road was an unknown landmark representing possible goal locations. In many cases, the route directions were accurately reflected in the environment; for instance, a Pharmacy located adjacent to a right turn. 
In other cases, however, we manipulated the environment to promote differential reliance on either landmarks or turn directions. Across three Experiments, we manipulated the source of route directions between three alternatives: no explicit information provided (control group), a GPS device, or a Human. Within the GPS device and Human sources, we further manipulated details regarding the source as being either low or high in reliability (GPS) and familiarity with the environment (Human). We measured differential reliance on landmark versus turn-based information for route directions that failed to unambiguously guide someone to a destination, and further asked whether individual differences in spatial preferences might predict this reliance.

\section{Experiment 1}

Our first Experiment examined spontaneous strategy adoption during conditions of spatial ambiguity when no descriptive information is provided about the source of directions. In this manner, participants read route directions and then decided where to travel by selecting a location on a map. Given mixed background literature we hypothesized that participants would show a reliable landmark- or direction-based strategy (Burns, 1997; Müller \& Wehner, 1988; Wehner, 1992), and that strategy selection might be predicted by individual differences in spatial preferences for landmarks versus direction-based (i.e., route-based, and/or survey-based preferences) information.

Method

Participants. Sixty Tufts University undergraduates (22 female; $\left.M_{\text {age }}=19.2\right)$ participated for monetary compensation. Informed written consent was obtained from all participants prior to the experiment in accordance with the guidelines established by the Institutional Review Board at Tufts University.

\section{Materials.}

Route Directions. We created 64 sentences that detailed route directions from a starting location to a final destination. Route directions named two landmarks (i.e., the final destination and a decision-point landmark), and a turn direction (i.e., left/right). For example: "To get to the theater, take a left at the bowling alley." To control for potential effects of order of mention, the 
presentation order of the turn direction and decision-point landmark information was reversed in half of the sentences (i.e., To get to the theater, at the bowling alley take a left).

Half of the route directions indicated a left turn; half indicated a right turn. Landmarks were selected from a set of 80 easily recognizable, salient, distinctive, and persistent/immobile locations (e.g., library, hospital, theater); each location was presented at least once, but not more than twice, as either a final destination or decision-point landmark. Across participants, each location appeared as both a final destination and a decision-point landmark.

Maps. See Figure 1 for sample stimuli. The route directions were paired with corresponding maps; each map was 1000x1000 pixels and consisted of (1) a black arrow on the bottom of the screen indicating the starting location and heading, (2) a road running vertically upward from the starting arrow, (3) two streets perpendicular to and intersecting the vertical street, one running to the left, the other to the right, (4) a decision-point landmark located adjacent to each intersection, and (5) a possible final destination located at the ends of each intersecting road.

Half of the maps were designed such that the first (i.e., bottom) intersecting street ran to the right (with the second street running to the left; Figure 1a); the other half was reversed (Figure 1b). Final destination landmarks were represented by icons of a question mark framed by a 130x130 pixel black rectangle. Decision-point landmarks were represented with icons collected from Microsoft Office clipart, converted to grayscale, resized, and framed by the same black rectangles. On each map, the decision-point landmarks were positioned either below or above the horizontally intersecting streets (see Procedure for details).

Retrospective Questions. We probed subjective degrees of relative reliance on various environment aspects by asking people to rate (on a scale from 1 to 7 , coded as -3 to 3 ) their relative dependence or attention to landmark versus turn direction information, the first versus second intersection, and right versus left turns.

Individual Differences Questionnaires. To predict landmark- versus direction-based strategies, we used an English-translated version of the German Questionnaire of Spatial Strategies (FRS; Münzer \& Hölscher, 2011), and the Questionnaire on Spatial Representation (QSR; Pazzaglia, Cornoldi, \& De Beni, 2000) to assess preferences for landmark, route and 
survey elements of the environment. The latter questionnaire further allows us to assess general sense of direction. Finally, we collected basic demographic information concerning age and gender.

\section{Procedure.}

Participants were seated at individual computer work stations, and all stimuli were presented on Dell 24' monitors (1920x2000) using SuperLab® software (v4.5; Cedrus, San Pedro, CA, USA). Upon arrival, participants provided informed consent, read the task instructions, completed a practice trial, and then proceeded to the main experiment. The main experiment consisted of sixty-four trials in which participants read route directions and then selected the final destination's most likely location on a map (Figure 1).

The 64 trials were separated into four blocks; within each block, participants completed 16 trials, in random order. We used this blocked design to increase procedural similarities across our experiments; in the following two experiments we manipulate reliability of direction sources across blocks. We also wanted to provide participants with the opportunity for a short break following each block. Each trial began with a route direction (e.g., To get to the pizza place, take a left at the gas station.). After a self-paced amount of time, participants clicked the mouse, which replaced the route directions with a grey box labeled "GO," positioned in the center of the monitor; this design was intended to control mouse cursor starting position and the focus of visual attention at trial onset. When they clicked in the center of the "GO" box, a map would appear. Then, participants were instructed to click on one of two icons on the map that represented a possible location for the final destination (spaced equidistant from the center of the monitor); response time and the $\mathrm{x}$ - and $\mathrm{y}$-coordinates of the mouse click were recorded. Once the destination location was selected, the next trial would begin. The order of blocks was counterbalanced across participants in a Latin square.

Critically, on half of the trials within each block the information detailed in the route directions was consistent (a non-dilemma trial), and on half the trials inconsistent (a dilemma trial), with the information presented on the map. On a dilemma trial, if the directions instructed: "To get to the theater, take a left at the bowling alley," the bowling alley (i.e., the decision-point landmark) would be adjacent to a right turn, and the left turn option would be adjacent to 
another, unrelated, landmark (e.g., a post office). For half of these dilemma trials the decisionpoint landmark was at the first intersection; on the other half of the trials the decision-point landmark was at the second intersection. Participants were forced to select a destination by clicking with the mouse on one of the two indeterminate landmarks (depicted with question marks); to make this decision they could either rely on the landmark information (e.g., taking a right turn at the bowling alley) or the turn information (e.g., taking a left turn at the post office).

Design Controls. To control for landmark position relative to the intersection, across trials we varied the maps to depict landmarks either before or after, and to the left or right of, an intersection. Finally, to control for order of mention, we varied syntax such that half of the trials mentioned the landmark first (e.g., Take a left at the bowling alley to get to the theater.) or turn first (e.g., At the bowling alley, take a left to get to the theater.). Follow-up analyses demonstrated that none of these controlling factors influenced behavioral results (across all 3 experiments), and they are thus not further analyzed.

After each participant completed the 64 trials, they rated a series of questions regarding differential reliance on landmarks versus turn directions, and then completed the spatial and demographic questionnaires.

Results

\section{Behavioral Data}

Non-Dilemma Trials. On average, participants showed high accuracy in selecting the correct final destination on the non-dilemma trials $(M=.99, S D=.03)$.

\section{Dilemma Trials.}

Response Times (in msec). Participants were slower to select final destinations during dilemma $(M=4269.2, S D=1992.6)$, as compared with non-dilemma trials $(M=2048.1, S D=$ 455.1). A paired t-test confirmed this difference, $t(59)=9.51, p<.001, d=1.81$.

Landmark versus Direction Strategy. The final destinations that were selected for dilemma trials were coded based on whether the selected location corresponded with the decision-point landmark or turn direction specified in the route directions (1=turn, $-1=$ landmark). 
In this manner, a score of 1 would indicate complete reliance on turn directions during all dilemma trials, a -1 would indicate complete reliance on landmarks, and a 0 would indicate a balanced split between the two strategies. We refer to this measure as the strategy score. Across all participants, the average strategy score was very close to $0(M=-.02, S D=.74)$; there was also very high variability in participants' responses (range -1 to 1). A frequency histogram of participants' strategy scores was bi-modal, with peaks at approximately -1 and 1 . That is, participants developed a strategy relying primarily on either direction or landmark information, and some alternated between the two types of information (see Figure 2).

Individual Differences: To assess whether individual differences predict reliance on landmarks versus turn directions, we asked whether strategy scores are predicted by gender ${ }^{1}$ or individual differences in spatial preferences and sense of direction. To examine gender, we tested for strategy score differences amongst males and females in an independent samples t-test; overall, males showed stronger reliance on landmarks $(M=-.32, S D=.58)$, and females on turn directions $(M=.16, S D=.78), t(58)=2.51, p<.05$. To examine spatial preferences and sense of direction, seven predictors were entered into a regression model: 1) FRS global-egocentric orientation subscale scores, 2) FRS survey subscale scores, 3) FRS cardinal directions subscale scores, 4) QSR landmark subscale scores, 5) QSR route subscale scores, 6) QSR survey subscale scores, and 7) QSR sense of direction score. Strategy score was the sole dependent measure. The regression model showed that of the 7 predictors, none carried significant predictive value, $F(7$, $59)=.401, p=.89, R=.23 ., p_{\min }=.44$. A follow-up regression including gender as an additional predictor showed a similar outcome.

Inconsistent Participant Preferences: Thirteen participants showed a relatively inconsistent reliance on landmarks or turn directions; that is, they tended to show differential reliance across trials, with strategy scores within .5 standard deviations of 0 (range -.35 to .35 ). Given that these particular participants tended to shift between landmark and turn reliance, we examined whether they showed any biases toward the first versus second intersection, or for the destination to the right or left. For the first analysis, we coded each dilemma trial decision as

\footnotetext{
${ }^{1}$ We did not make specific predictions regarding the influence of gender on strategy selection, but provide this analysis to afford comparison to extant literature (e.g., Lawton, 1994; Sandstrom, Kaufman, \& Huettel, 1998).
} 
reflective of choosing to turn at the first (-1) versus second (1) intersection. Overall, participants tended to select the second intersection during dilemma trials $(11 / 13$ participants; $M=.43, S D=$ .35). In other words, if the referenced landmark was at the first intersection, participants tended to turn at the second intersection, showing a direction-based strategy. In contrast, when the referenced turn direction was at the first intersection, participants tended to turn at the second intersection, showing a landmark-based strategy. For the second analysis (left versus right turns), we coded each dilemma trial decision as reflective of choosing to turn to the left (-1) versus right (1). Overall, participants showed no reliable bias to the left or right $(M=-.016 ; S D=.16)$. Thus, inconsistent strategy selection can be largely attributed to these participants demonstrating a strong reliance on the second intersection, regardless of the nature of the dilemma.

Time and Strategy Adoption. We also assessed whether participants changed strategy adoption over the course of the 32 dilemma trials. In other words, it could be the case that participants began without a clear strategy and then adopted a single strategy later in the experiment; it could also be the case that they began with a single strategy and then changed strategies. To examine these possibilities, we separated the 32 dilemma trials into four time bins, each containing 8 trials (i.e., bin 1: trials 1-8; bin 2: trials 9-16; bin 3: trials 17-24; bin 4: trials 25-32). Strategy scores were then entered into a repeated-measures ANOVA with a single 4level factor (Time: bin 1, bin 2, bin 3, bin 4). This analysis revealed a non-significant effect of Time, $F(3,177)=.56, p=.64, \eta^{2}<.01$. Thus, there was no evidence that participants adopted reliably different strategies as a function of time.

\section{Subjective Response Data}

Subjective Reliance on Landmark-versus Direction-based Strategies. Recall that we asked participants to rate their subjective degrees of reliance on landmark versus turn information, the first versus second intersection, and left versus right turns. Subjective ratings of landmark versus turn reliance were highly correlated with strategy score data (Pearson's $r=.84$, $p<.001$ ), suggesting strong correspondence between subjective and actual strategy adoption. Subjective ratings of first versus second intersection reliance showed no strong tendency in either direction $(M=-0.1, S D=.88)$. Ratings of left versus right turn reliance showed a small but reliable subjective preference for right, versus left, turns $(M=.37, S D=.94$; one-sample t-tests versus $0: t(59)=3.03, \mathrm{p}<.01)$. 


\section{Experiment 1 Discussion}

Our first experiment examined landmark- and direction-based strategies when participants attempted to disambiguate flawed route directions. Participants read route directions and then attempted to confirm the destination on a basic route map, similar to what one might do when attempting to relate verbal directions to a tourist map immediately prior to or during navigation. Overall, participants tended to apply either a landmark- or direction-based strategy, with only a minority of participants switching strategies across trials. Furthermore, participants seemed subjectively aware of their strategies, given ratings of relative reliance that patterned strongly along with behavioral data. In an effort to account for these results, we examined whether several participant characteristics would predict a tendency to rely upon a landmarkversus direction-based strategy. Overall, males showed a stronger reliance on landmarks, and females on turn directions. However, there was no suggestion that individual spatial preferences or sense of direction predicted any particular pattern of reliance. Thus, our first experiment suggests that in the absence of information about the source of directions (i.e., not explicitly a device or a human), participants vary widely in terms of landmark- versus direction-based strategies, and individual spatial preferences do not predict this pattern.

\section{Experiment 2}

Our second experiment examined whether Experiment 1 results extend to conditions involving an automated direction-giver. In many real-world scenarios, people get verbal directions from an automated GPS device that provides information about turn directions and, potentially, landmark identities. Indeed prototype navigational aids, such as in-vehicle and handheld global positioning (GPS) devices, are attempting to incorporate landmarks to be consistent with human navigation strategies, perceived value to drivers, and potential to improve usability (Burnett, 2000). A number of studies have demonstrated that including landmarks in navigation systems increases their effectiveness, efficiency and user satisfaction. For instance, navigators who follow routes with versus without reference to landmarks positioned at intersections show reduced turning errors (Bengler, Haller, \& Zimmer, 1994; Pauzié et al., 1997), fewer glances to a GPS device, lower cognitive workload ratings (Burnett, 2000), and higher confidence in navigation decisions (Alm, Nilsson, Järmark, Savelid, \& Hennings, 1992). This early research has provided impetus for including landmarks in next-generation navigation technologies. 
Though systems that include landmarks are frequently used in specialized and restricted scale environments, such as museums or college campus tours, no commercially available navigation systems have fully achieved landmark-inclusive route guidance. It is also clear that systems such as street view (Google ${ }^{\mathrm{TM}}$ Maps) are highly data intensive, license-restricted, and can suffer from poor critical landmark visibility, making them less suitable for real-time in-vehicle or hand-held navigation (Hile, Vedantham, Cuellar, Liu, Gelfand, Grzeszczuk, \& Borriello, 2008; WaltherFranks, 2007). The present work asks whether direction-followers will prove differentially reliant on landmark- versus turn direction-based information from GPS devices. We also ask whether such reliance might be related to the implied reliability of the device. In some cases a device may be highly reliable, including updated maps, whereas another device might be underdeveloped, outdated, or otherwise unreliable. It could be the case that the implied reliability of a system might modulate reliance on landmarks versus turn directions; for instance, early (e.g., beta) versions of a new GPS device might be deemed relatively unreliable, and this might encourage reliance on the general direction of an objective, rather than specifics about landmark identities and locations.

\section{Method}

Participants. Sixty Tufts University undergraduates (40 female; $M_{\text {age }}=20.5$ ) participated for monetary compensation. Informed written consent was obtained from all participants prior to the experiment in accordance with the guidelines established by the Institutional Review Board at Tufts University.

\section{Materials.}

The route directions, maps, retrospective ratings, and individual differences measures were identical to those used in Experiment 1.

GPS Device Descriptions. Characteristics of the GPS device varied between two conditions implying low versus high reliability. In the low reliability condition, participants were informed that the GPS device is "a first version of a new GPS device and is untested for accuracy and details." In the high reliability condition, participants were informed that the GPS device is "the $4^{\text {th }}$ version of a popular GPS device that has proven accuracy and details." Two generic brands and logos were developed for each low and high reliability system, to accompany the 
descriptions; in this manner, there were two versions of the low reliability, and two versions of the high reliability, devices.

Device Ratings. As a manipulation check, we assessed participants' impressions of the described device. On 7-point Likert scales, participants rated how much they would like using and how reliable they considered each system.

\section{Procedure.}

The 64 trials were separated into four blocks, corresponding to each of the four GPS devices (two low reliability brands, and two high reliability brands). At the beginning of each block, the device was elucidated in terms of its stage of development (beta release versus $4^{\text {th }}$ release) and reliability (untested versus proven accuracy and details). Within each block, participants completed 16 trials, in random order, verbally related to the GPS device (e.g., PATHDragon 4.0 says: To get to the pizza place, take a left at the gas station.). After each block, participants would complete the device ratings. All other procedures matched those of Experiment 1.

Results

\section{Behavioral Data}

Non-Dilemma Trials. On average, participants showed high accuracy in selecting the correct final destination on the non-dilemma trials $(M=.98, S D=.03)$.

\section{Dilemma Trials.}

Response Times (in msec). Participants were slower to select final destinations during dilemma $(M=3662.2, S D=1541.3)$, as compared with non-dilemma trials $(M=2042.9, S D=$ 571.4). A paired t-test confirmed this difference, $t(59)=9.99, p<.001, \mathrm{~d}=1.81$.

Landmark versus Direction Strategy. As in Experiment 1, we calculated strategy scores ranging from - 1 (complete landmark reliance) to 1 (complete turn reliance). Across all participants, the average strategy score deviated significantly from $0(M=.19, S D=.72 ; t(59)=$ $2.04, p<.05, \mathrm{~d}=.26$; there was also very high variability in participants' responses (range -1 to 1). A frequency histogram of participants' strategy scores showed a negative skew, with a peak 
at 1 . That is, participants tended to take a turn-direction strategy, but some showed a landmark strategy or alternated between the two (see Figure 3).

GPS Device Reliability. To evaluate whether implied GPS device reliability modulated strategy scores, we compared mean scores between the low versus high reliability conditions. Overall, these conditions produced highly similar strategy scores $\left(M_{\text {low }}=.17, S D_{\text {low }}=.73 ; M_{\text {high }}\right.$ $\left.=.20, S D_{\text {high }}=.72 ; t(59)=.96, p=.34\right)$. This was also the case when testing only within the first block of trials, before participants may come to realize that each device was associated with an equal proportion of dilemma trials $\left(M_{\mathrm{low}}=.23, S D_{\mathrm{low}}=.79 ; M_{\mathrm{high}}=.20, S D_{\mathrm{high}}=.76 ; t(59)=.47\right.$, $p=.64)$.

Individual Differences. As in Experiment 1, to assess whether individual differences predict reliance on landmarks versus turn directions, we asked whether strategy scores are predicted by gender or individual differences in spatial preferences and sense of direction. To examine gender, we tested for strategy score differences amongst males and females in an independent samples t-test; overall, males and females did not differ in reliance on landmarks versus turn directions $(p=.17)$. To examine spatial preferences and sense of direction, we entered the seven mean-centered predictors into a regression model, with strategy scores as the sole dependent measure. The regression model showed that of the 7 predictors, none carried significant predictive value, $F(7,59)=.26, p=.97, R=.18, p_{\min }=.28$. A follow-up regression including gender as an additional predictor showed a similar outcome.

Inconsistent Participant Preferences: Fourteen participants showed a relatively inconsistent reliance on landmarks or turn directions; that is, they tended to show differential reliance across trials, with strategy scores within .5 standard deviations of 0 (range -.36 to .36) Given that these particular participants tended to shift between landmark and turn reliance, we examined whether they showed any biases toward the first versus second intersection, or for the destination to the right or left. Overall, participants showed no reliable tendency to select the first or second intersection during dilemma trials $(M=.12, S D=.21)$, or select the left versus right turn direction $(M=-.01, S D=.12)$. Thus, inconsistent strategy selection cannot be attributed to reliance on intersection order or direction. 
Time and Strategy Adoption. We also assessed whether participants changed strategy adoption over the course of the 32 dilemma trials. A repeated-measures ANOVA with a single 4level factor (Time: bin 1, bin 2, bin 3, bin 4) revealed a non-significant effect of Time, $F(3,177)$ $=.84, p=.48, \eta^{2}<.01$. Thus, there was no evidence that participants adopted different strategies as a function of time.

\section{Subjective Response Data}

Subjective Reliance on Landmark- versus Direction-based Strategies. Recall that we asked participants to rate their subjective degrees of reliance on landmark versus turn information, the first versus second intersection, and left versus right turns. Subjective ratings of landmark versus turn reliance were highly correlated with strategy score data (Pearson's $r=.81$, $p<.001$ ), suggesting strong correspondence between subjective and actual strategy adoption. Subjective ratings of first versus second intersection reliance showed no strong tendency in either direction $(M=-0.12, S D=1.18)$; similarly, ratings of left versus right turn reliance showed no strong tendency $(M=.08, S D=.69$.

Device Ratings. Participants rated how much they would like using each system, as well as how reliable they considered each system. There was a trend toward participants giving higher ratings to the more reliable devices, for both liking ratings $\left(M_{\text {low }}=2.32, S D_{\text {low }}=1.23 ; M_{\text {high }}=\right.$ $\left.2.58, S D_{\text {high }}=1.33\right)$, and reliability ratings $\left(M_{\text {low }}=2.67, S D_{\text {low }}=1.16 ; M_{\text {high }}=2.81, S D_{\text {high }}=\right.$ 1.29 ), though none of these differences reached significance ( $p$ 's $>.06$ ). Of course, given that the proportion of dilemma (or "faulty") trials was consistent across all devices, one might not expect substantial differences in participant ratings. In other words, though participants were told that some devices were inherently better than others, each device was just as likely to provide faulty directions.

\section{Experiment 2 Discussion}

Our second experiment examined whether receiving directions from a GPS device would produce different patterns of landmark versus turn reliance relative to Experiment 1 results with an unknown direction source. We also asked whether the described reliability of the GPS device, varying from low to high reliability, would influence these results. Two primary findings emerged from this experiment. First, in contrast to Experiment 1, participants showed a skewed 
distribution of landmark versus turn reliance, with the majority of participants demonstrating turn direction reliance. Recall that Experiment 1 showed a relatively even split of landmark versus turn reliance, and some predictive value of participant gender. In contrast, the present results suggested a relatively consistent reliance on turn directions, and gender and individual preferences did not predict the extent of this reliance; by revealing the nature of the direction source we introduced a situational factor that seemed to override gender-based strategy differences. Second, subjective ratings of reliance on landmarks versus turn directions were strongly correlated with actual reliance, with participants seemingly aware of their biased reliance on a single spatial cue.

\section{Experiment 3}

Our third and final experiment was modeled after Experiment 2 with the exception of using human direction givers rather than GPS devices. If people deem GPS devices as particularly fallible when it comes to accurately representing landmark identities or locations, they might show very different propensities when directions are from a human source. Indeed people are particularly error prone when it comes to giving route directions (Lovelace et al., 1999), and they can show high prevalence of left/right confusion (Jordan, Wustenberg, JaspersFeyer, Fellbrich, \& Peters, 2006; Sholl \& Egeth, 1981). In contrast, humans are quite accurate when referring to landmarks along a route (Michon \& Denis, 2001), and seem particularly reliant on landmarks during navigation (Klippel \& Winter, 2005; Michon \& Denis, 2001; Tversky \& Lee, 1999). Given these results, we expect that participants provided with directions from a human source will show a different strategy relative to Experiments 1 and 2. Specifically, we expect that they will be more likely to attribute inconsistencies to turn-direction errors derived from left/right confusion, rather than landmark errors. If this is the case, results will show evidence for landmark reliance, and this will be further revealed in subjective responses. Analogous to Experiment 2, we also manipulated the ostensible spatial knowledge of human direction givers by describing the individuals as either relatively naïve (i.e., new to the area) or experienced with the neighborhood. Given Experiment 2 results showing no evidence for GPS characteristics influencing strategy selection, we did not anticipate any strong influence of direction giver characteristics. 


\section{Method}

Participants. Sixty Tufts University undergraduates (37 female; $M_{\text {age }}=19.6$ ) participated for monetary compensation. Informed written consent was obtained from all participants prior to the experiment in accordance with the guidelines established by the Institutional Review Board at Tufts University.

\section{Materials.}

The route directions, maps, retrospective ratings, and individual differences measures were identical to those used in Experiment 1.

Human Direction-Giver Descriptions. Characteristics of the people providing directions varied between two conditions implying low versus high spatial knowledge. In the low knowledge condition, participants were informed that the direction-giver was visiting and has only been in the town for a "couple of days;" in the high knowledge condition, the directiongiver was "born and raised" in the town. To control for potential effects of direction-giver gender, we crossed knowledge with whether the direction-giver was either male (i.e., James or Michael) or female (i.e., Elizabeth or Sarah) by using gender-specific names.

Direction-Giver Ratings. As in Experiment 2, we assessed participants' impressions of the direction giver. On 7-point Likert scales, participants rated how much they would like using and how reliable they considered each direction giver.

\section{Procedure.}

The 64 trials were separated into four blocks, corresponding to each of the four directiongivers. At the beginning of each block, the person was described in terms of their implied low versus high spatial knowledge (details above). Within each block, participants completed 16 trials, in random order, verbally related to the direction-giver (e.g., James says: To get to the pizza place, take a left at the gas station.). All other procedures matched those of Experiment 2. 
Results

\section{Behavioral Data}

Non-Dilemma Trials. On average, participants showed high accuracy in selecting the correct final destination on the non-dilemma trials $(M=.99, S D=.02)$.

Dilemma Trials.

Response Times (in msec). Participants were slower to select final destinations during dilemma $(M=3869.2, S D=1703.9)$, as compared with non-dilemma trials $(M=2072.9, S D=$ 510.9). A paired t-test confirmed this difference, $t(59)=9.92, p<.001, \mathrm{~d}=1.28$.

Landmark versus Direction Strategy. As in the preceding experiments, we calculated strategy scores ranging from -1 (complete landmark reliance) to 1 (complete turn reliance). Across all participants, the average strategy score deviated significantly from $0(M=-.57, S D=$ $.53 ; t(59)=8.28, p<.001, \mathrm{~d}=1.06$; there was also very high variability in participants' responses (range -1 to 1). A frequency histogram of participants' strategy scores showed a strong positive skew, with a peak at -1 . That is, the majority of participants showed a landmark strategy, and some others showed a turn direction strategy or alternated between the two (see Figure 4).

Direction Giver Knowledge. To evaluate whether implied spatial knowledge modulated strategy scores, we compared mean scores between the low versus high knowledge conditions. Overall, these conditions produced highly similar strategy scores $\left(M_{\text {low }}=-.58, S D_{\text {low }}=.57 ; M_{\text {high }}\right.$ $\left.=-.55, S D_{\text {high }}=.57 ; t(59)=.65, p=.52\right)$. Note that direction-giver gender did not modulate strategy scores and is thus not further considered.

Individual Differences: As in Experiments 1 and 2, to assess whether individual differences predict reliance on landmarks versus turn directions, we asked whether strategy scores are predicted by gender or individual differences in spatial preferences and sense of direction. To examine gender, we tested for strategy score differences amongst males and females in an independent samples t-test; overall, males and females did not differ in reliance on landmarks versus turn directions $(p=.11)$. To examine spatial preferences and sense of direction we entered seven mean-centered predictors into a regression model, with strategy scores as the sole dependent measure. The regression model showed no predictive value, $F(7,59)=.27, p=$ 
$.91, R=.18$. Of the 7 predictors, none carried significant predictive value $\left(p_{\min }=.39\right)$. A followup regression including gender as an additional predictor showed a similar outcome.

Inconsistent Participant Preferences: Twenty participants showed a relatively inconsistent reliance on landmarks or turn directions; that is, they tended to show differential reliance across trials, with strategy scores within .5 standard deviations of 0 (range -.26 to .26 ). Given that these particular participants tended to shift between landmark and turn reliance, we examined whether they showed any biases toward the first versus second intersection, or for the destination to the right or left. Overall, participants showed no reliable tendency to select the first or second intersection during dilemma trials $(M=.09, S D=.19)$, or select the left versus right turn direction $(M=-.002, S D=.08)$. Thus, inconsistent strategy selection cannot be attributed to reliance on intersection order or direction.

Time and Strategy Adoption. We also assessed whether participants changed strategy adoption over the course of the 32 dilemma trials. A repeated-measures ANOVA with a single 4level factor (Time: bin 1, bin 2, bin 3, bin 4) revealed a non-significant effect of Time, $F(3,177)$ $=1.98, p=.12, \eta^{2}<.01$. Thus, there was no evidence that participants adopted different strategies as a function of time.

Comparing Experiments 1-3. To compare strategy scores as a function of the direction source, we compared strategy scores in a one-way ANOVA with three groups: Control Group (Experiment 1), GPS Group (Experiment 2), and Human Group (Experiment 3). The ANOVA was significant, $F(2,179)=20.29, p<.001, \eta^{2}=.19$, suggesting that direction source influenced strategy scores. Follow-up analyses using independent-samples t-tests demonstrated a marginal difference between the Control and GPS group, $t(118)=1.55, p=.06, d=.28$, and significant differences between the Control and Human group, $t(118)=6.56, p<.001, d=1.2$, and GPS and Human group, $t(118)=4.65, p<.001, d=.86$.

\section{Subjective Response Data}

Subjective Reliance on Landmark- versus Direction-based Strategies. Recall that we asked participants to rate their subjective degrees of reliance on landmark versus turn information, the first versus second intersection, and left versus right turns. Subjective ratings of landmark versus turn reliance were highly correlated with strategy score data (Pearson's $r=.81$, 
$p<.001$ ), suggesting strong correspondence between subjective and actual strategy adoption. Subjective ratings of first versus second intersection reliance showed no strong tendency in either direction $(M=-0.16, S D=.98)$; similarly, ratings of left versus right turn reliance showed no strong tendency $(M=.07, S D=.53)$.

Direction Giver Ratings. Participants rated how much they liked, and how reliable they considered, each direction giver. Paired t-tests showed that whereas liking ratings did not differ by implied knowledge of the direction giver $\left(M_{\text {low }}=3.29, S D_{\text {low }}=1.16 ; M_{\text {high }}=3.47, S D_{\text {high }}=\right.$ $1.02 ; p=.28)$, participants gave higher reliability ratings when direction givers were described as relatively knowledgeable $\left(M_{\text {low }}=2.76, S D_{\text {low }}=.81 ; M_{\text {high }}=3.12, S D_{\text {high }}=1.28 ; p=.02\right)$.

\section{Experiment 3 Discussion}

Our third experiment examined whether receiving directions from a human source would produce different patterns of landmark versus turn reliance relative to Experiments 1 and 2. We hypothesized that the relative directional fallibility of humans would lead participants to rely preferentially on landmarks rather than turn directions. This hypothesis was confirmed, with results showing a reliable reliance on landmarks rather than turn directions. This pattern was robust, with approximately $70 \%$ of the participants showing landmark reliance on at least $75 \%$ of dilemma trials, and did not vary as a function of individual preferences or sense of direction. Subjective ratings again correlated strongly with actual reliance, and several participants commented that humans are particularly prone to confusing left/right directions, but less likely to misremember a landmark.

\section{General Discussion}

Receiving route directions and attempting to use them to navigate a novel environment is a common spatial task. In many cases the task results in effectively finding a goal destination; in other cases, the route directions fail and you are forced to make decisions given conflicting information. This study examined a basic instantiation of this failure, in which navigators had to rely on either landmark- or direction-based strategies, because the information conflicted. We examined these issues in three different situations: 1) when route directions are provided by an undefined (control) source without explicit reference to an automated system or human directiongiver, 2) when route directions are provided by a GPS device, and 3) when route directions are 
provided by a human. Without any particular information about the source of directions, Experiment 1 demonstrated highly varied reliance on either landmark or turn directions, with participants tending to select one strategy and apply it across a range of dilemma trials.

Experiments 2 and 3, however, demonstrated that when details are revealed about the nature of the direction-giver, large strategy differences emerge. With details regarding a GPS device, participants tended to use a strategy based on turn directions; with details regarding a human direction-giver, participants relied strongly on landmarks. It seems to be the case that participants deemed the GPS device likely flawed in terms of landmark details, but that human directiongivers are more likely flawed in terms of turn directions. We also found evidence that participant gender influences spontaneous strategy adoption in the absence of source details, but that situational factors revealing the source of information can serve to override gender influences and increase the application of a single strategy. In contrast, the measured individual spatial preferences did not appear to predict strategy adoption. We also found no compelling evidence that varied implied reliability within a given direction source influenced strategy adoption. Overall, the studies reveal clear differences in the extent to which people rely on landmarks versus turn directions under uncertain conditions, based largely on the nature of the information source (i.e., GPS versus human). We consider these effects within the context of theoretical models of spatial decision making and trust in automated systems, and then turn to implications for the development of spatial decision technologies that convey landmark information to users.

\section{Landmark versus Turn Reliance}

Extant research suggests differential importance of landmarks, turns, and general directions toward guiding navigation. In general, this research has demonstrated that route descriptions are comprised of at least two fundamental characteristics: minimal and essential landmark information, and a set of instructions that guides movement between landmarks (Daniel et al., 2003, 2009; Daniel \& Denis, 1998). The extent to which route descriptions successfully guide navigation is largely contingent on accurate links between descriptive elements such as landmark identity, and prescriptive elements such as turn directions (Daniel et al., 2009). We also know that landmarks themselves are particularly essential for guiding navigation in that they provide salient perceptual cues for recognizing decision points and destinations (Presson \& Montello, 1988). In fact, navigation performance suffers when 
landmarks are strategically removed during environment learning or navigation (Collett, 1996; Gardony, Brunyé, Mahoney, \& Taylor, 2011; Ruddle, Volkova, Mohler, \& Bülthoff, 2011; Müller \& Wehner, 1988; Wehner, 1992). In the absence of expected landmarks, people must rely on other aspects of the environment, such as the presumed general direction of a destination (Biegler \& Morris, 1996; Foo et al., 2005). Unfortunately, this type of global knowledge about environment structure is impoverished for unfamiliar environments (Brunyé \& Taylor, 2008; Golledge \& Spector, 1978; Kuipers et al., 2001; Sholl, 1987). In the absence of details regarding the direction source, the present results support the notion that people rely on both landmarks and turn directions when uncertain. In fact, participants were evenly split between those who adopted a landmark- versus turn-based strategy; it seems to be the case that under these relatively ambiguous conditions participants tend to adopt a single heuristic or 'rule of thumb' to apply during conditions of decision uncertainty. This particular finding supports the notion that spatial uncertainty can trigger reliance on learned adaptations that increase cognitive economy and simplify an otherwise complex problem (e.g., Gigerenzer \& Goldstein, 1996; Gray et al., 2006). We provide evidence, however, that spatial strategies during uncertainty can vary widely as a function of situational factors, in this case knowledge regarding the information source. To our knowledge, our research is the first to specifically investigate whether information regarding the source of route directions modulates reliance on different spatial cues during decision making. We suggest that stereotypes (or perhaps factual knowledge; Jordan et al., 2006; Sholl \& Egeth, 1981) regarding the fallibility of various sources of route directions can activate heuristics that selectively reject particular spatial cues; with humans, people appear to reject the use of turn information, and with GPS people reject the use of landmarks. Our conclusions motivate continuing work in relatively realistic navigation contexts, and contribute to research demonstrating the importance of considering spatial heuristics when explaining and predicting spatial behavior (Bailenson et al., 1998, 2000; Brunyé et al., 2010, 2012a, 2012b; Dalton, 2003; Hochmair \& Frank, 2002; Sadalla \& Staplin, 1980; Senevirante \& Morrall, 1986).

Interestingly, we found no evidence that the implied reliability or knowledge level of a given source influenced strategy selection. Across experiments, we varied whether a GPS device was implied as low (i.e., a first version of a new device) versus high (i.e., a time-proven device) reliability, and whether a human source was implied as low (i.e., new to the area) versus high (i.e., experienced with the area) knowledge. Overall, participants showed no reliable reliance on 
these source details when making decisions under uncertainty; for the most part, participants trusted GPS devices to lead them in the correct overall direction, and humans to accurately remember landmark identities, regardless of their implied reliability or experience with an area. This is a surprising result that demonstrates the power of source modality in driving navigator perceptions of fallibility, overriding any particulars about individual device or human reliability.

Of course, it could be the case that our design, given equal proportions of correct versus incorrect directions across source modalities, may have unintentionally masked any influence of relative source reliability. Though future designs may find value in examining this possibility, we think it is unlikely given that no effects were found in the first trial block before participants could likely realize that all of the information sources provided faulty directions. Thus, we believe our results speak most strongly to differences in individuals' trust in human versus automated systems to provide accurate information (Muir, 1994).

Though our landmarks were always positioned immediately adjacent to a turn option, in some cases this may not reflect actual landmark to turn relationships. For instance, a navigator might encounter a landmark located directly across the street from a specified turn direction, though there is an opposing turn direction in the distance. In such cases it is unclear what types of strategies might emerge. Continuing research may find value in extending our method to cases where landmarks are distant from turn options. Similarly, continuing research in our laboratories is developing virtual environment versions of ambiguous navigation scenarios, asking whether introducing relatively real-world perceptual features (e.g., distant landmarks and turns) might influence strategy selection. For instance, when a specified landmark is not found, might a navigator select the immediate turn option, or invest additional resources into exploring distant options? Such questions might reveal important distinctions between the present data and behaviors that might emerge in relatively real-world scenarios.

\section{Individual Differences and Strategy Selection}

We began this study by suggesting that navigator preferences for landmark- versus routeor survey-based preferences might predict strategy application under conditions of spatial uncertainty. This hypothesis was based on literature suggesting that individuals have general propensities towards focusing on (primarily in memory) different environmental elements (i.e., Münzer \& Hölscher, 2011; Pazzaglia et al., 2000). In our work, we expected that strong 
preferences for attending to and memorizing particular types of spatial information would translate to differential reliance on this information during decision making. However, across our studies we found no strong evidence that spatial preferences predict what navigators do under conditions of uncertainty. Indeed we only found one piece of evidence, in only one experiment, suggesting that males rely more strongly on landmarks relative to females; this particular finding is somewhat surprising given that males are typically more reliant on large-scale geometric spatial cues whereas females are relatively reliant on landmark cues (Lawton, 1994; Sandstrom et al., 1998). We note that our failure to find predictive value of individual differences might be specific to relating route directions to map-based depictions of an environment. The allocentric nature of our map stimuli might have encouraged consideration of global directions, failing to accommodate those with particular preferences (e.g., route preference). It could be the case that more realistic first-person conditions that afford reliance on a wider range of cues may elicit a stronger influence of individual preferences on navigation decisions. Moreover, many of the currently available measures of spatial preference tend to focus on the manner in which information is represented in memory, and how people apply spatial memories to navigation tasks. Our focus, however, was on determining the information people use when they are completely naïve to an environment and solving a problem prior to actual navigation. Participants could not rely upon environmental memory, but rather were forced to use the limited information available to them during the criterion task. To our knowledge, there are no currently available questionnaires that index differential reliance on environmental elements in completely naïve navigators, though this seems worthy of future development efforts.

\section{Spatial Decision Support Technologies}

Prototype spatial support technologies, such as in-vehicle and hand-held global positioning (GPS) devices, are attempting to incorporate landmarks due to their consistency with human navigation strategies, perceived value to drivers, and potential to improve usability (Burnett, 2000; Burnett, Smith, \& May, 2001, Raubal \& Winter, 2002). A number of studies have demonstrated that including landmarks in navigation systems can increase their effectiveness, efficiency and user satisfaction. However, it is also clear that landmark-aware systems are highly data intensive, license-restricted and can suffer from poor critical landmark visibility, making them less suitable for real-time in-vehicle or hand-held navigation devices 
(Hile et al., 2008; Walther-Franks, 2007). In response to these limitations, many prototype systems, such as those developed for mobile phone applications (Hile et al., 2008), focus on embedding landmark photographic imagery into turn-by-turn instructions. For instance, Dräger and Koller (2012) used the open-source OpenStreetMap resource to identify and extract imagery of landmarks adjacent to turns, and depicted these images along with turn-by-turn guidance while participants navigated in a driving simulator. Compellingly, the prototype system was able to perform this integrative process continually and without perceived interruption on behalf of the navigator. Results demonstrated fewer and briefer glances away from the simulated environment, without compromising navigation accuracy or efficiency, when the system included landmark depictions. Thus, there is mounting evidence not only for the utility but also the potential feasibility of complementing route directions with landmark imagery collected only from route turning points.

As landmark-inclusive navigation technologies become more feasible, our results speak to practical considerations in their design and development. Work in human-computer interaction has consistently demonstrated that high levels of user reliance on automated systems (including navigation systems; St. George \& Nendick, 1997) can lead to a tendency not to monitor (or understand; Lee \& See, 2004) system performance, a condition sometimes termed automation induced complacency (Endsley \& Kiris, 1995; Parasuraman, Molloy, \& Singh, 1993). While navigators may show high reliance on referenced landmarks during navigation, introducing errors in the system may cause dramatic shifts towards disregarding landmark information. Thus, landmarks with low permanence, such as small businesses, become a particular problem for landmark reliance. For instance, navigators faced with ambiguities regarding landmarks or turns may quickly disregard landmark information in favor of turn directions, potentially being led astray. Thus, our work suggests considerations for the design of landmark-inclusive navigation systems; to avoid reinforcing stereotypes regarding GPS landmark fallibility (and forcing turn reliance), near-future systems might be practically restricted to landmarks with relatively high permanence such as museums, parks, statues or monuments (Burnett, 2000).

\section{Conclusion}

The present study uniquely demonstrated differential reliance on landmark- versus direction-based strategies when navigators encounter conditions of uncertainty. Across our 
experiments we found reliable evidence that most participants tend to select a single strategy, relying on either landmarks or turn directions during conditions of ambiguity; a minority of participants in each experiment were relatively flexible in strategy adoption. Further, strategies adopted can be dramatically different when the source of directions is an automated system versus human; each of these cases is characterized by implied fallibility regarding landmarks or turn directions, respectively. Interestingly, individual differences in spatial preferences did not predict these patterns. These results thus demonstrate that differential reliance on landmarks versus turn directions during navigation can be strongly predicted by perceptions of system (GPS versus human) fallibility, and these results appear robust across a range of individual spatial preferences. 


\section{References}

Allen, G. L. (2000). Principles and practices for communicating route knowledge. Applied Cognitive Psychology, 14(4), 333-359.

Alm, H., Nilsson, L., Jármark, S., Savelid, J., \& Hennings, U. (1992). The effects of landmark presentation on driver performance and uncertainty in a navigation task - A field study. Swedish Prometheus, Tech. Rep. No. S/IT-4. Linköping, Sweden: VTI.

Bailenson, J. N., Shum, M. S., \& Uttal, D. H. (1998). Road climbing: Principles governing asymmetric route choices on maps. Journal of Environmental Psychology, 18(3), 251-264.

Bailenson, J. N., Shum, M. S., \& Uttal, D. H. (2000). The initial segment strategy: A heuristic for route selection. Memory \& Cognition, 28(2), 306-318.

Bengler, K., Haller, R., \& Zimmer, A. (1994). Experimental optimisation of route guidance information using context information. Paper presented at the First World Congress on Applications of Transport and Intelligent Vehicle Highway Systems. Paris, France.

Biegler, R., \& Morris, R. (1996). Landmark stability: studies exploring whether the perceived stability of the environment influences spatial representation. Journal of Experimental Biology, 199(1), 187-193.

Brunyé, T. T., Andonova, E., Meneghetti, C., Noordzij, M. L., Pazzaglia, F., Wienemann, R., ... \& Taylor, H. A. (2012a). Planning routes around the world: International evidence for southern route preferences. Journal of Environmental Psychology, 32(4), 297-304.

Brunyé, T. T., Mahoney, C. R., Gardony, A. L., \& Taylor, H. A. (2010). North is up (hill): Route planning heuristics in real-world environments. Memory \& Cognition, 38(6), 700-712.

Brunyé, T. T., \& Taylor, H. A. (2008). Extended experience benefits spatial mental model development with route but not survey descriptions. Acta Psychologica, 127(2), 340-354.

Burnett, G. E. (2000). "Turn right at the traffic lights": The requirement for landmarks in vehicle navigation systems, The Journal of Navigation, 53(3), 499-510 
Burnett, G., Smith, D., \& May, A. (2001). Supporting the navigation task: Characteristics of 'good' landmarks. Contemporary Ergonomics, 1, 441-446.

Burns, P.C. (1997). Navigation and the older driver. Unpublished PhD dissertation, Loughborough University, UK.

Chown, E., Kaplan, S., \& Kortenkamp, D. (1995). Prototypes, location, and associative networks (PLAN): Towards a unified theory of cognitive mapping. Cognitive Science, 19(1), 1-51.

Collett, T. (1996). Insect navigation en route to the goal: multiple strategies for the use of landmarks. Journal of Experimental Biology, 199(1), 227-235.

Dalton, R. C. (2003). The secret is to follow your nose: Route path selection and angularity. Environment and Behavior, 35(1), 107-131.

Daniel, M. P., \& Denis, M. (1998). Spatial descriptions as navigational aids: A cognitive analysis of route directions. Kognitionswissenschaft, 7(1), 45-52.

Daniel, M. P., Przytula, E., \& Denis, M. (2009). Spoken versus written route directions. Cognitive processing, 10, 201-203.

Daniel, M. P., Tom, A., Manghi, E., \& Denis, M. (2003). Testing the value of route directions through navigational performance. Spatial Cognition and Computation, 3, 269-289.

Denis, M. (1997). The description of routes: A cognitive approach to the production of spatial discourse. Current Psychology of Cognition, 16, 409-458.

Denis, M., Pazzaglia, F., Cornoldi, C., \& Bertolo, L. (1997). Spatial discourse and navigation: An analysis of route directions in the city of Venice. Applied Cognitive Psychology, 13, 145174.

Dräger, M., \& Koller, A. (2012). Generation of landmark-based navigation instructions from open-source data. In Proceedings of the 13th Conference of the European Chapter of the Association for Computational Linguistics (pp. 757-766). Association for Computational Linguistics. 
Duckham, M., Winter, S., \& Robinson, M. (2010). Including landmarks in routing instructions. Journal of Location Based Services, 4(1), 28-52.

Endsley, M. R., \& Kiris, E. O. (1995). The out-of-the-loop performance problem and level of control in automation. Human Factors: The Journal of the Human Factors and Ergonomics Society, 37(2), 381-394.

Foo, P., Warren, W. H., Duchon, A., \& Tarr, M. J. (2005). Do humans integrate routes into a cognitive map? Map- versus landmark-based navigation of novel shortcuts. Journal of Experimental Psychology: Learning, Memory, and Cognition, 31(2), 195-215.

Frankenstein, J., Büchner, S. J., Tenbrink, T., \& Hölscher, C. (2010). Influence of geometry and objects on local route choices during wayfinding. In Spatial Cognition VII (pp. 41-53). Berlin, Heidelberg: Springer.

Gardony, A., Brunyé, T. T., Mahoney, C. R., \& Taylor, H. A. (2011). Affective states influence spatial cue utilization during navigation. Presence: Teleoperators and Virtual Environments, 20(3), 223-240.

Gärling, T. (1995). Urban Cognition. Waltham, MA: Academic Press.

Gärling, T., Book, A., \& Lindberg, E. (1984). Cognitive mapping of large-scale environments the interrelationship of action plans, acquisition, and orientation. Environment and Behavior, 16(1), 3-34.

Gärling, T., \& Golledge, R. G. (2000). Cognitive mapping and spatial decision making. Cognitive Mapping: Past, Present, and Future (pp. 44-65). London: Routledge.

Gigerenzer, G., \& Goldstein, D. G. (1996). Reasoning the fast and frugal way: models of bounded rationality. Psychological Review, 103(4), 650.

Golding, J. M., Graesser, A. C., \& Hauselt, J. (1996). The process of answering direction-giving questions when someone is lost on a university campus: The role of pragmatics. Applied Cognitive Psychology, 10(1), 23-39. 
Golledge, R. G., \& Spector, A. N. (1978). Comprehending the urban environment: Theory and practice. Geographical Analysis, 10(4), 403-426.

Gray, W. D., Sims, C. R., Fu, W. T., \& Schoelles, M. J. (2006). The soft constraints hypothesis: a rational analysis approach to resource allocation for interactive behavior. Psychological Review, 113(3), 461.

Hile, H., Vedantham, R., Cuellar, G., Liu, A., Gelfand, N., Grzeszczuk, R., \& Borriello, G. (2008, December). Landmark-based pedestrian navigation from collections of geotagged photos. In Proceedings of the 7th international conference on mobile and ubiquitous multimedia (pp. 145-152). ACM.

Hirtle, S., Richter, K. F., \& Srinivas, S. (2010). This is the tricky part: When directions become difficult. Journal of Spatial Information Science, 1, 53-73.

Hochmair, H., \& Frank, A. U. (2000). Influence of estimation errors on wayfinding-decisions in unknown street networks-analyzing the least-angle strategy. Spatial Cognition and Computation, 2(4), 283-313.

Hölscher, C., Tenbrink, T., \& Wiener, J. M. (2011). Would you follow your own route description? Cognitive strategies in urban route planning. Cognition,121(2), 228-247.

Janzen, G., Schade, M., Katz, S., \& Herrmann, T. (2001). Strategies for detour finding in a virtual maze: The role of the visual perspective. Journal of Environmental Psychology, 21, 149-163.

Jordan, K., Wüstenberg, T., Jaspers-Feyer, F., Fellbrich, A., \& Peters, M. (2006). Sex differences in left/right confusion. Cortex, 42(1), 69-78.

Kahneman, D., \& Tversky, A. (1982). The psychology of preferences. Scientific American.

Klippel, A., \& Winter, S. (2005). Structural salience of landmarks for route directions. In A. G. Cohn \& D. M. Mark (Eds), Spatial Information Theory, volume 3693 of Lecture Notes in Computer Science, pages 347-362. Berlin, Germany: Springer. 
Kuipers, B. (2001). The skeleton in the cognitive map: A computational hypothesis.

In Proceedings of the Third International Symposium (pp. 10-11).

Kwan, M-P., Golledge, R. G., \& Speigle, J. (1996). Information representation for driver decision support systems. University of California Transportation Center, Working Paper UCTC, 333. Retrieved from: http://escholarship.org/uc/item/7zz0q3mw

Lawton, C. A. (1994). Gender differences in way-finding strategies: Relationship to spatial ability and spatial anxiety. Sex Roles, 30(11-12), 765-779.

Lawton, C. A. (1996). Strategies for indoor wayfinding: The role of orientation. Journal of Environmental Psychology, 16(2), 137-145.

Lee, J. D., \& See, K. A. (2004). Trust in automation: Designing for appropriate reliance. Human Factors, 46, 50-80.

Lipshitz, R., \& Strauss, O. (1997). Coping with uncertainty: A naturalistic decision-making analysis. Organizational Behavior and Human Decision Processes, 69(2), 149-163.

Lloyd, R. (1997). Spatial cognition: Geographic environments (Vol. 39). Berlin, Germany: Springer.

Lovelace, K. L., Hegarty, M., \& Montello, D. R. (1999). Elements of good route directions in familiar and unfamiliar environments. In C. Freksa \& D. M. Mark (Eds.), Spatial Information Theory: Cognitive and computational foundations of geographic information science. Berlin, Germany: Springer.

March, J. G. (1994). Primer on decision making: How decisions happen. Simon and Schuster.

Maule, A. J., \& Svenson, O. (1993). Theoretical and empirical approaches to behavioral decision making and their relation to time constraints. In Time Pressure and Stress in Human Judgment and Decision Making (pp. 3-25). Berlin: Springer.

Michon, P. E., \& Denis, M. (2001). When and why are visual landmarks used in giving directions. In D. R. Montello (Ed), Spatial Information Theory: Foundations of Geographic Information Science (pp. 292-305). Berlin, Germany: Springer. 
Millonig, A., \& Schechtner, K. (2007). Developing landmark-based pedestrian-navigation systems. Intelligent Transportation Systems, IEEE Transactions on,8(1), 43-49.

Montello, D. R. (2005). Navigation. In P. Shah \& A. Miyake (Eds.), The Cambridge handbook of visuospatial thinking (pp. 257-294). Cambridge: Cambridge University Press.

Muir, B. M. (1994). Trust in automation: Part I. Theoretical issues in the study of trust and human intervention in automated systems. Ergonomics, 37, 1905-1922.

Müller, M., \& Wehner, R. (1988). Path integration in desert ants, Cataglyphis fortis. Proceedings of the National Academy of Sciences, 85(14), 5287-5290.

Münzer, S., \& Hölscher, C. (2011). Entwicklung und validierung eines fragebogens zu räumlichen strategien [Development and validation of a questionnaire of spatial strategies]. Diagnostica, 57(3), 111-125.

Mychalcewycz, P. (2009). Man follows GPS... to the edge of a cliff. Switched (AOL Tech News). Retrieved from: http://www.switched.com/2009/03/25/man-follows-gps-to-the-edgeof-a-cliff/

O'Keefe, J., \& Nadel, L. (1978). The hippocampus as a cognitive map. Oxford, UK: Oxford University Press.

Parasuraman, R., Molloy, R., \& Singh, I. L. (1993). Performance consequences of automationinduced'complacency'. The International Journal of Aviation Psychology, 3(1), 1-23.

Passini, R. (1980). Wayfinding in complex buildings: an environmental analysis. ManEnvironment Systems, 10, 31-40.

Pauzie, A., Daimon, T., Bruyas, M. P., \& Trauchessec, R. (1997). How to design landmarks for guidance systems?. In Mobility for Everyone. $4^{\text {th }}$ World Congress on Intelligent Transport Systems, 2266. Berlin.

Payne, J. W. (1976). Task complexity and contingent processing in decision making: An information search and protocol analysis. Organizational behavior and human performance, 16(2), 366-387. 
Pazzaglia, F., Cornoldi, C., \& De Beni, R. (2000). Differenze individuali nella rappresentazione dello spazio e nell'abilità di orientamento: Presentazione di un questionario autovalutativo [Individual differences in the representation of space and in the ability to orient: Presentation of a self-report questionnaire]. Giornale italiano di psicologia, 27(3), 627-0.

Pazzaglia, F., \& De Beni, R. (2001). Strategies of processing spatial information in survey and landmark-centred individuals. European Journal of Cognitive Psychology, 13(4), 493-508.

Presson, C. C., \& Montello, D. R. (1988). Points of reference in spatial cognition: Stalking the elusive landmark. British Journal of Developmental Psychology, 6(4), 378-381.

Raubal, M. \& Winter, S. 2002. Enriching Wayfinding Instructions with Local Landmarks. In M. Egenhofer \& D. Mark (Eds.), Geographic Information Science - Second International Conference GIScience 2002, Boulder, CO, USA, September 2002. Lecture Notes in Computer Science 2478, pp. 243-259, Springer, Berlin.

Rehrl, K., Häusler, E., \& Leitinger, S. (2010). Comparing the effectiveness of GPS-enhanced voice guidance for pedestrians with metric-and landmark-based instruction sets. In Geographic Information Science (pp. 189-203). Springer Berlin Heidelberg.

Ruddle, R. A., Volkova, E., Mohler, B., \& Bülthoff, H. H. (2011). The effect of landmark and body-based sensory information on route knowledge. Memory \& cognition, 39(4), 686-699.

Russell, J. A., \& Snodgrass, J. (1987). Emotion and the environment.Handbook of Environmental Psychology, 1, 245-280.

Russell, J. A., \& Ward, L. M. (1982). Environmental psychology. Annual Review of Psychology, 33(1), 651-689.

Sadalla, E. K., \& Staplin, L. J. (1980). The perception of traversed distance: intersections. Environment and Behavior, 12(2), 167-182.

Sandstrom, N. J., Kaufman, J., \& A Huettel, S. (1998). Males and females use different distal cues in a virtual environment navigation task. Cognitive Brain Research, 6(4), 351-360. 
Schmid, F., Kuntzsch, C., Winter, S., Kazerani, A., \& Preisig, B. (2010). Situated local and global orientation in mobile you-are-here maps. In Proceedings of the 12th international conference on human computer interaction with mobile devices and services (pp. 83-92). ACM.

Schroder, C. J., Mackaness, W. A., \& Gittings, B. M. (2011). Giving the 'right' route directions: The requirements for pedestrian navigation systems. Transactions in GIS, 15(3), 419-438.

Senevirante, P. N., \& Morrall, J. F. (1986). Analysis of factors affecting the choice of route pedestrians. Transportation Planning \& Technology, 10, 147-159.

Shelton, A. L., \& McNamara, T. P. (2004). Orientation and perspective dependence in route and survey learning. Journal of Experimental Psychology: Learning, Memory, and Cognition, 30(1), 158.

Sholl, M. J. (1987). Cognitive maps as orienting schemata. Journal of Experimental Psychology: Learning, Memory, and Cognition, 13(4), 615.

Sholl, M. J., \& Egeth, H. E. (1981). Right-left confusion in the adult: A verbal labeling effect. Memory \& Cognition, 9(4), 339-350.

St George, R., \& Nendick, M. (1997). GPS='got position sussed'- Some challenges for engineering and cognitive psychology in the general aviation environment. Engineering Psychology and Cognitive Ergonomics, 1, 81-91.

Steck, S. D., \& Mallot, H. A. (2000). The role of global and local landmarks in virtual environment navigation. Presence: Teleoperators and Virtual Environments, 9, 69-83.

Streeter, L. A., Vitello, D., \& Wonsiewicz, S. A. (1985). How to tell people where to go: comparing navigational aids. International Journal of Man-Machine Studies, 22(5), 549-562.

Taylor, H. A., Brunyé, T. T., \& Taylor, S. T. (2008). Spatial mental representation: implications for navigation system design. Reviews of Human Factors and Ergonomics, 4(1), 1-40.

Tenbrink, T., Bergmann, E., \& Konieczny, L. (2011). Wayfinding and description strategies in an unfamiliar complex building. In L. Carlson, C. Hölscher, \& T.F. Shipley (Eds.), 
Proceedings of the 33rd Annual Conference of the Cognitive Science Society. Austin, TX: Cognitive Science Society, pp 1262-1267.

Timmermans, H. (1983). Noncompensatory decision rules and consumer spatial choice behaviour: A test of predictive ability. The Professional Geographer, 35, 449-485.

Tom, A., \& Denis, M. (2003). Referring to landmark or street information in route directions: What difference does it make? In W. Kuhn, M. F. Worboys \& S. Timpf (Eds.), Spatial information theory: Foundations of geographic information science (pp. 384-397). Berlin: Springer.

Trullier, O., Wiener, S. I., Berthoz, A., \& Mayer, J. A. (1997). Biologically-based artificial navigation systems: Review and prospects. Progress in Neurobiology, 51, 483-544.

Tversky, B., \& Lee, P. U. (1999). Pictorial and verbal tools for conveying routes. In Spatial information theory. Cognitive and computational foundations of geographic information science (pp. 51-64). Springer Berlin Heidelberg.

Vanetti, E. J., \& Allen, G. L. (1988). Communicating Environmental Knowledge The Impact of Verbal and Spatial Abilities on the Production and Comprehension of Route Directions. Environment and Behavior, 20(6), 667-682.

Walther-Franks, B. (2007). Augmented reality on handhelds for pedestrian navigation. Unpublished Masters Thesis, Universität Bremen, Bremen.

Wehner, R. (1992). Arthropods. In Animal homing (pp. 45-144). Netherlands: Springer. 


\section{Figure Captions}

Figure 1. Example map stimuli depicting landmarks, routes and destination options.

Figure 2. Experiment 1 (control source) frequency histogram depicting distribution of strategy scores.

Figure 3. Experiment 2 (GPS source) frequency histogram depicting distribution of strategy scores.

Figure 4. Experiment 3 (human source) frequency histogram depicting distribution of strategy scores. 


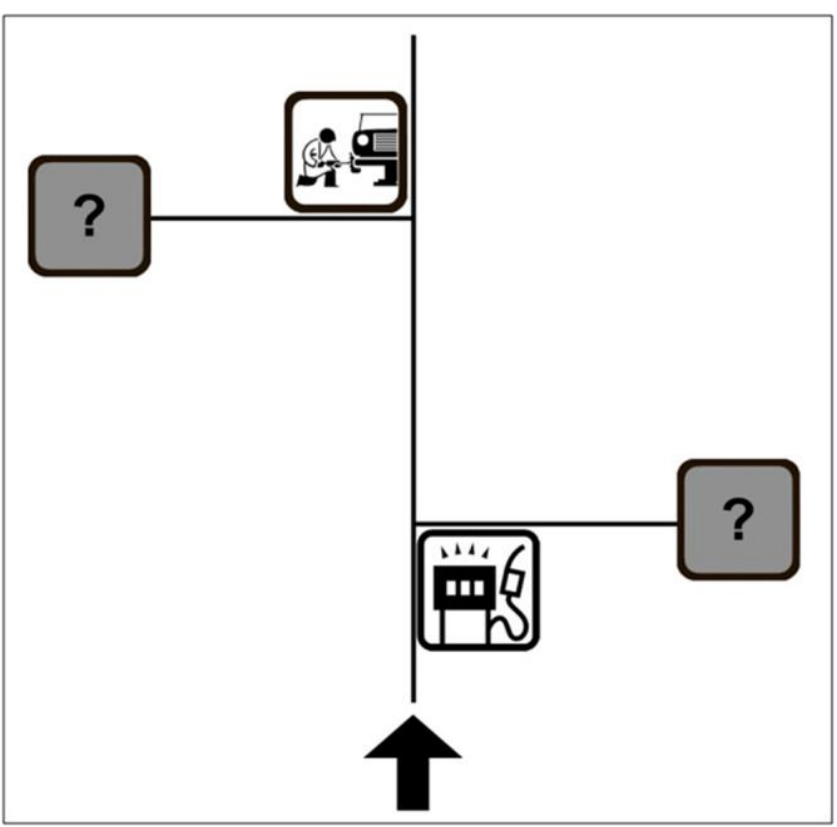

1a

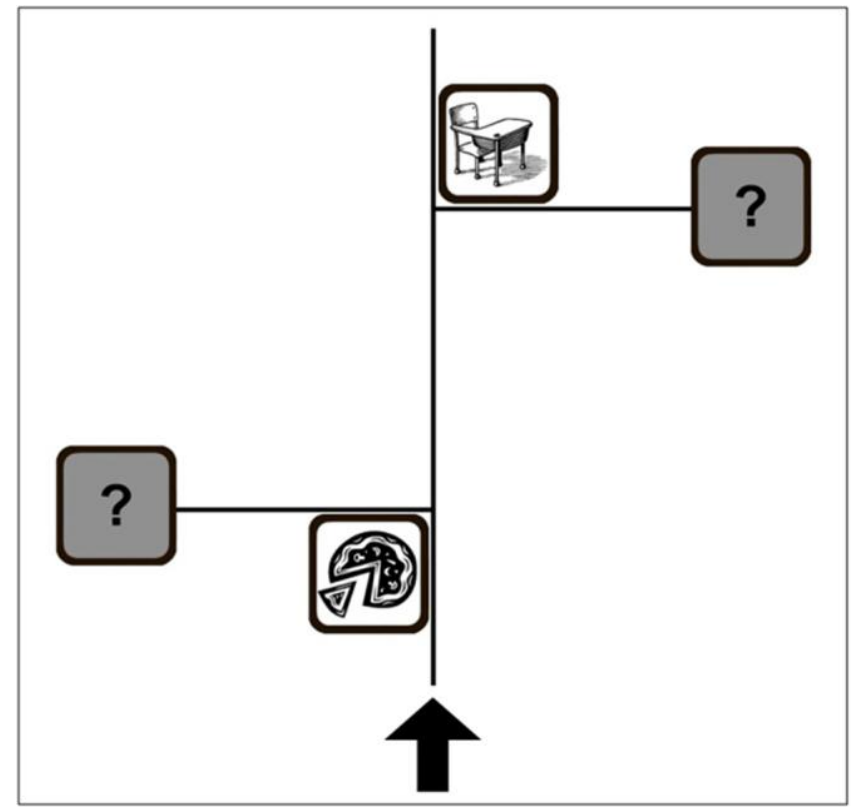

$1 b$ 


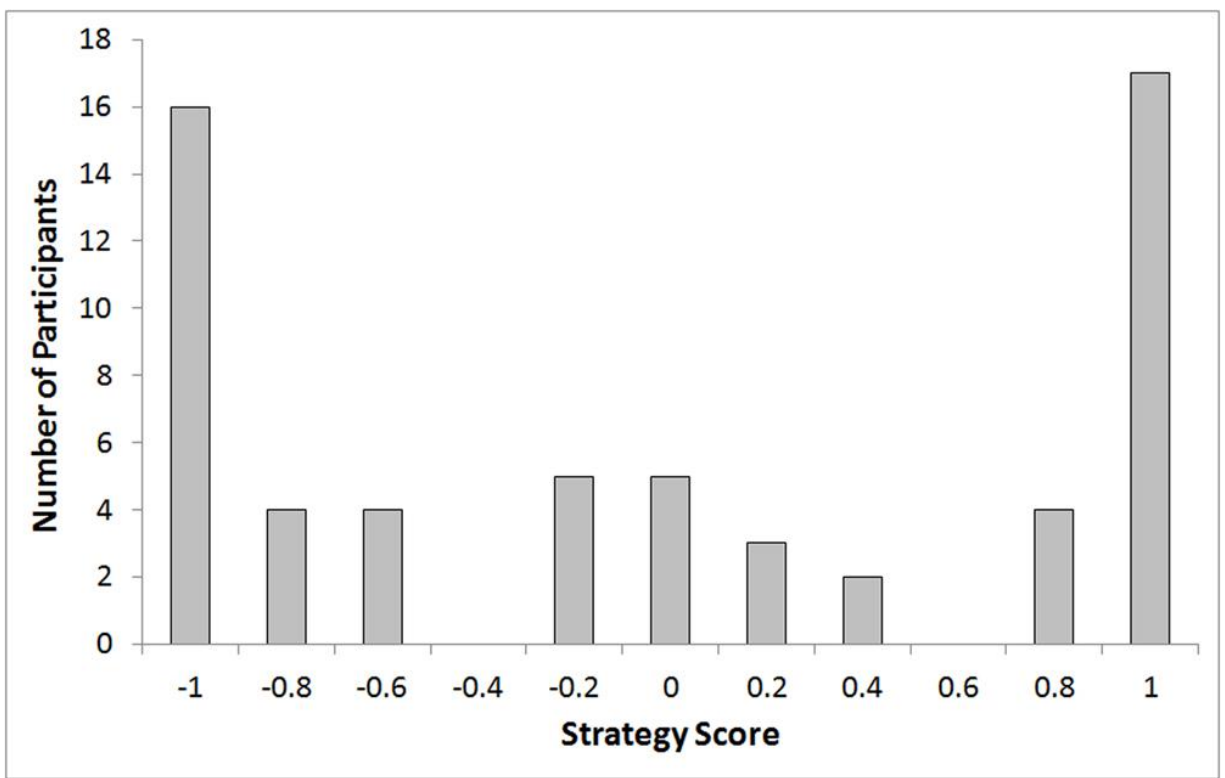




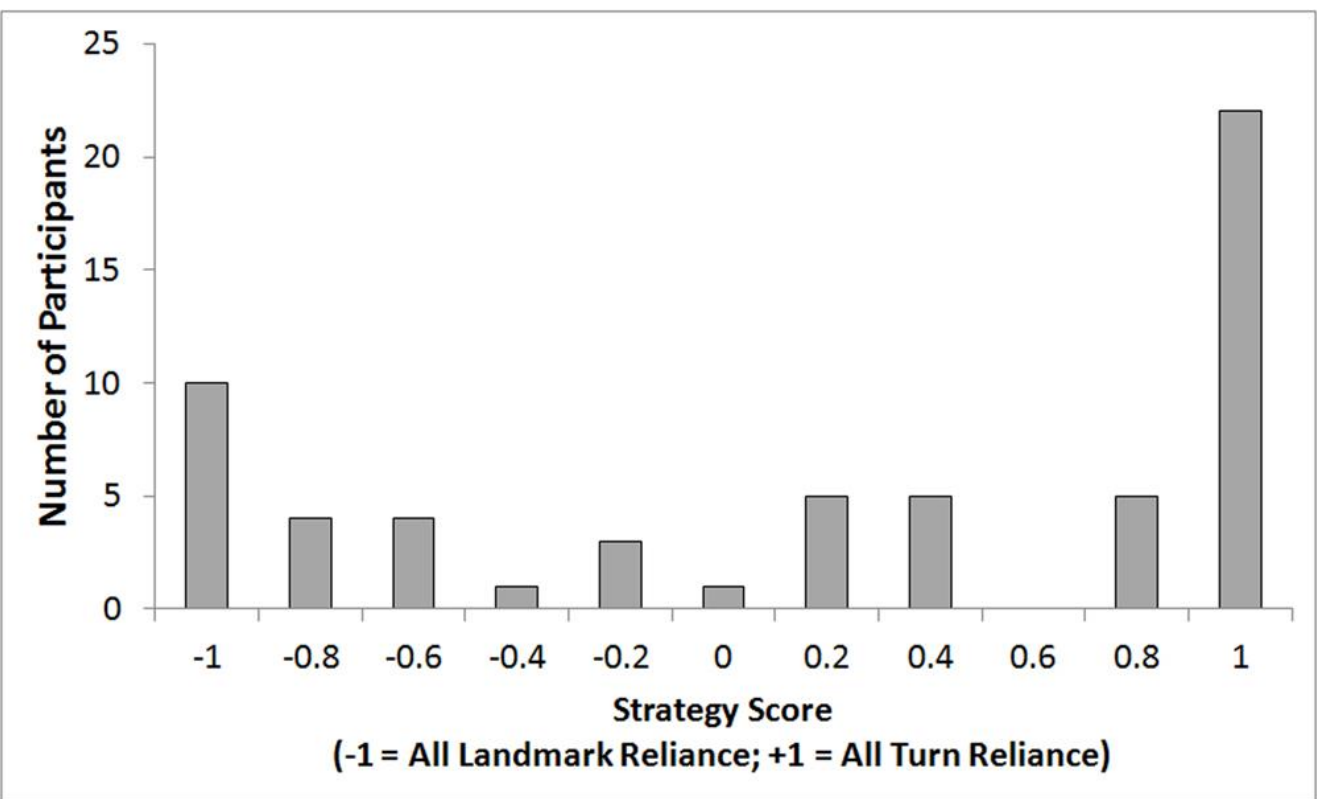




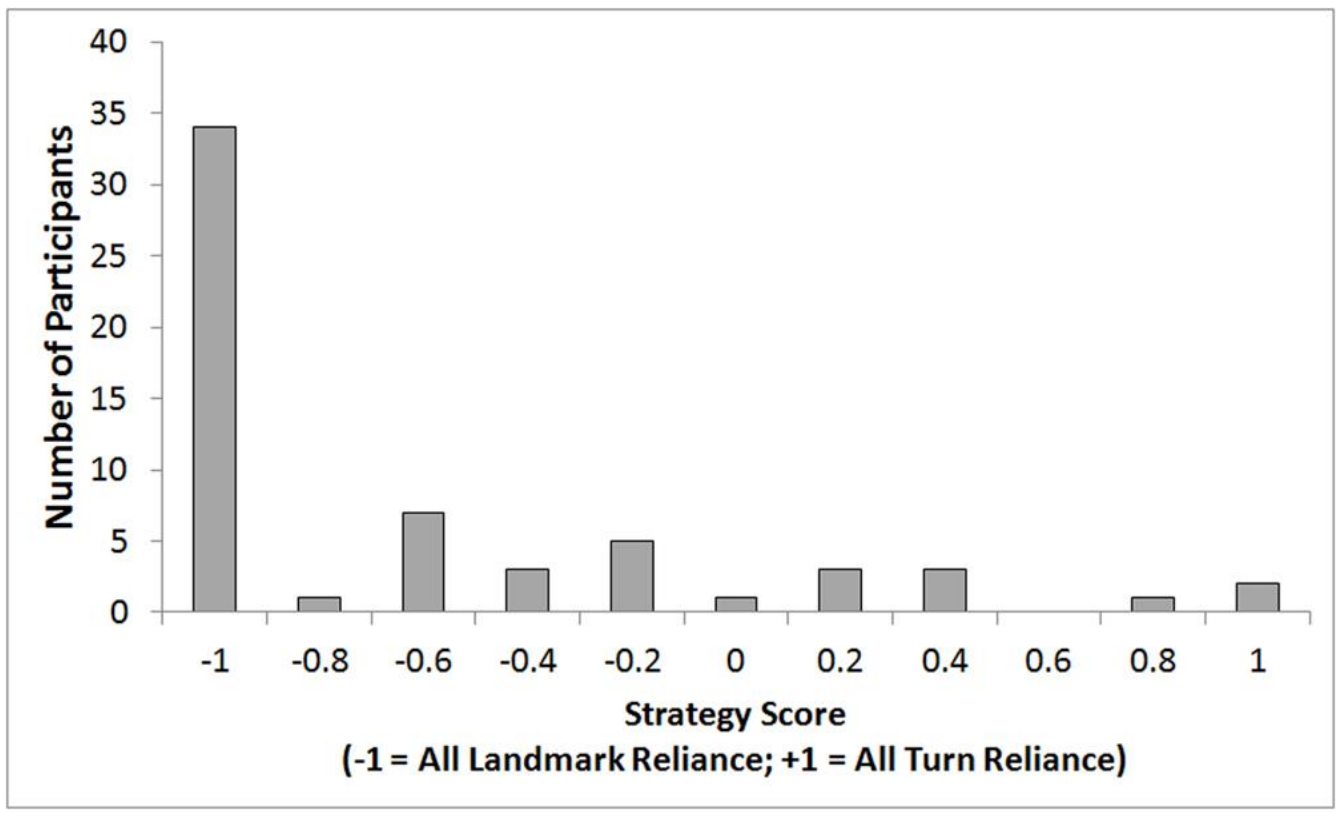

